\title{
Long-term changes and drivers of biodiversity in Atlantic oakwoods
}

\author{
Fraser J.G. Mitchell \\ Forest Ecology and Management \\ Volume 307, 1 November 2013, Pages 1-6
}

\begin{abstract}
Atlantic oakwoods are of high conservation value in western Europe. Developing effective conservation management policies requires data on the dynamics of woodland over long time scales. Such data are not available through monitoring or documentary records so palaeoecological data have been investigated. Pollen and charcoal data from four western Irish woods covering up to 7000 years have been analysed to provide information on changes in alpha and beta diversity, rates of change and fire history over time. These analyses reveal that the most significant changes in biodiversity relate to the loss of Pinus sylvestris from these woods followed by their exploitation and subsequent management for timber, charcoal and tan bark. The structure and composition of the present day woods still display a strong legacy from their exploitation and this raises important questions relating to the long-term conservation management of these woods.
\end{abstract}

\section{Keywords}

- Atlantic oakwoods;

- Palaeoecology;

- Biodiversity management;

- Forest dynamics;

- Forest exploitation

\section{Introduction}

The Atlantic oakwoods of western Europe have been regarded as temperate rainforest due to the high degree of oceanicity that they enjoy and the associated richness and luxuriance of their bryophyte and fern floras (Baarda, 2005 and Kelly, 2005). They have distinctive biodiversities (Hall and Stone, 2005 and Kelly, 2005) and consequently are listed as Annex 1 habitats (EU code 91A0) under the European Union's Habitats Directive (E.U., 1992) which affords their protection under national conservation designations in the relevant countries. Atlantic oakwoods have been developing throughout the postglacial (Brewer et al., 2005). 
Although they are defined by their oceanic climate, palaeoecological evidence from Ireland, Scotland and Wales demonstrates that they have been profoundly influenced by human impacts in the past (Edwards, 1986, Mitchell, 1988, Mitchell, 1990, Little et al., 1996 and Sansum, 2004). Vegetation surveys have also highlighted disturbance in the form of grazing and timber extraction as being the principal drivers of structural changes to Atlantic oakwoods throughout Britain as well as in the Basque country of Northern Spain (Onaindia et al., 2004 and Amar et al., 2010). Both climate change and human induced impacts are identified as significant threats to the future continuity of this conservation resource (Hall and Stone, 2005 and Kelly, 2005).

Addressing the mitigation of these threats requires the investigation of longterm data that cover temporal scales that are commensurate with that of the forest cycle of tree generations. Although some long-term monitoring datasets do exist (Silvertown et al., 2010) they are never of sufficient quality or longevity to address the dynamics of forest successions. Despite this, Keith et al. (2009) have used long-term data to demonstrate taxonomic homogenization of woodland communities in southern England over a 70 year period. Additionally, resurveys of British woodlands after two to four decades have revealed structural changes associated with a range of drivers that vary in both space and time (Peterken and Jones, 1987, Peterken and Jones, 1989, Kirby et al., 2005, Mihok et al., 2009 and Amar et al., 2010). These investigations raise the question of how much the biodiversity of Atlantic oakwoods has been impacted by the human exploitations that they suffered in recent centuries or indeed by the nonintervention conservation policies that have been adopted in recent decades. Detailed floristic data covering these times, as well as from earlier, to provide a baseline do not exist but some relevant information can be obtained from palaeoecological sources (Mitchell, 2011).

Pollen analysis has the advantage that long time records (thousands of years) of vegetation change can be reconstructed from a single site. The main restriction of this approach is poor spatial resolution (Mitchell, 2011). Traditional pollen analysis uses sediments from large lakes or bogs which collect pollen from a radius of tens of kilometres. The pollen from numerous vegetation communities is mixed before deposition and so identifying dynamics in a single community is restricted by uncertainties. Surface sample measurements, and modelling studies have shown, however, that the pollen records contained within small hollows in forests are dominated by pollen from a more local source area within a $100 \mathrm{~m}$ radius (Sugita, 1994). Small hollow pollen analysis from forested sites thus provides data on forest dynamics at the forest stand scale (Bradshaw, 2007 and Overballe-Petersen and Bradshaw, 2011). Such data that are chronologically controlled can be likened to the analysis of vegetation patterns in forest stand quadrats through time. The pollen data derived from such investigations is, however, a proxy for vegetation. Differences in production, dispersal and preservation of pollen across species is an important issue (Seppä, 2007). In addition, pollen is most consistently identified to genus rather than species level, 
and occasionally only to family level, so the taxonomic resolution of pollen data do not match that of quadrat data from vegetation surveys. Recent advances in modelling pollen dispersal at landscape and local scales (Sugita, 2007a and Sugita, 2007b) provides an approach for deriving vegetation compositional data for woodland communities from small hollow pollen data (e.g. Nielsen and Odgaard, 2010, Sugita et al., 2010 and Overballe-Petersen et al., 2013) but the empirical data on pollen dispersal for the relevant taxa required to drive these models in Atlantic oakwoods are not yet available. Consequently it is necessary to rely on pollen data as the vegetation proxy for this investigation. Despite these restrictions, pollen do provide proxy data of vegetation change over millennial timescales that can be analysed to address compositional change in forested communities (Birks, 2007).

In this paper changes in the biodiversity of Atlantic oakwoods are quantified over millennial timescales from a series of sites located along the west coast of Ireland. This permits the investigation of the research question: how has human exploitation of Atlantic forests impacted on their biodiversity and what is the long-term legacy of this exploitation?

\section{Methods}

Pollen records were selected from small hollows in Irish Atlantic oakwoods that had independent dating and covered at least the last 3000 years. This resulted in the selection of 4 pollen records (Table 1). Further details on the sites and generation of the pollen records can be found in the original publications (Table 1).

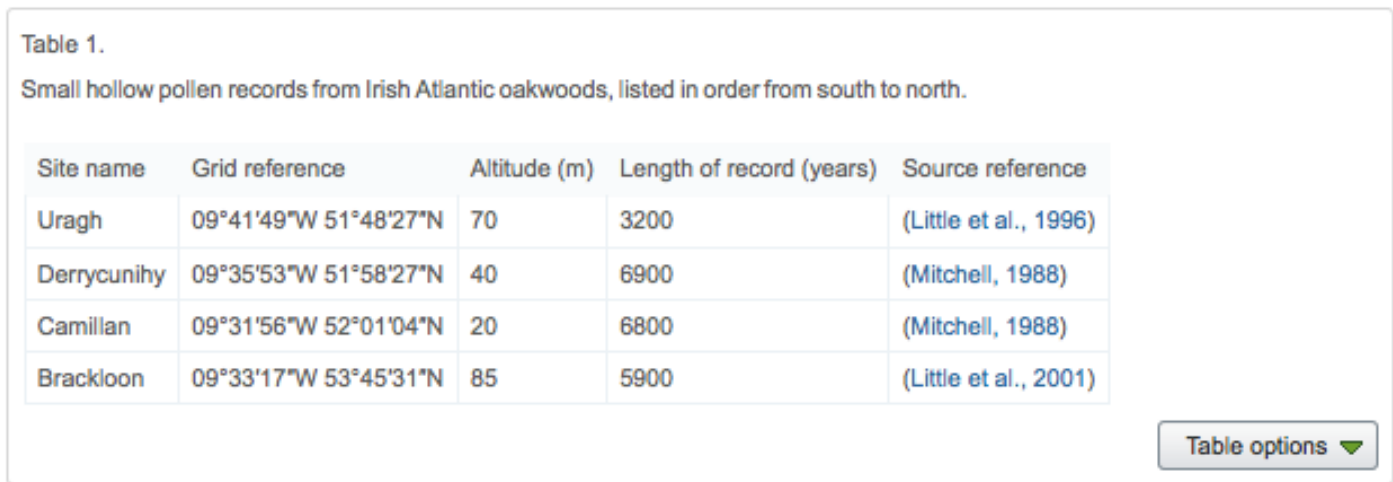

The combined dataset for the four sites is represented by 101 pollen samples and a total of 93 different pollen taxa. Chronologies were developed for each site using the original radiocarbon dates run through the Bayesian modelling technique Bchron (version 3.1.4 using the IntCal09 calibration curve) which uses a stochastic linear interpolation process (Haslett and Parnell, 2008). From this process it was possible to derive a date for each pollen sample (Supplementary material). 
Ordination of the pollen data using non-metric multidimensional scaling (NMS) in PC-ORD 6.08 (McCune and Mefford, 2011) was used to explore the relationship between pollen samples. The taxon richness of each pollen sample can be derived from the number of pollen taxa identified but since the number of pollen grains identified varies across samples it is necessary to rarefy the taxon richness to a constant pollen sum for each site (Birks and Line, 1992).

Rarefaction of the data was computed with the rarefaction function within the vegan package (Oksanen et al., 2012) in R (R Core Team, 2012) to derive an alpha diversity measure for each sample (RareN). RareN was thus scaled to the lowest pollen count from the samples within a site. The rate of change (ROC) between adjacent pollen samples was quantified by the squared chord distance (Grimm and Jacobson, 1992). The chronologies were then used to scale ROC to units per 100 years. The surface pollen sample for each site was assumed to represent present day conditions. The Sørensen (Bray-Curtis) distance in NMS ordination space for each site was used as a measure of change (beta diversity) in older samples compared to the present day. To facilitate presentation and further analysis, the derived RareN, ROC and beta diversity metrics were pooled across the four sites and averaged for each 1000 year period. In addition to the pollen data, microscopic charcoal data derived from the pollen slides are also available from each site (see original publications for details). The site chronologies were used to derive the charcoal accumulation rate (CHAR) for each sample and these data were also averaged for each 1000 year period. Differences among 1000 year periods were tested for using the non-parametric Kruskall Wallis test followed by post hoc Mann-Whitney U tests with Sidak's adjustment for multiple tests.

The degree of biodiversity heterogeny between, and within, the 1000 year periods was assessed through Multi-Response Permutation Procedures (MRPP) in PC-ORD 6.08 (McCune and Mefford, 2011). The Sørensen (Bray-Curtis) distance measure was used on the pollen data sets. MRPP derives a test statistic, $\mathrm{T}$, with its associated p-value which indicates the separation between time periods (more negative values represent stronger separation). MRPP also calculates the chance-corrected within-time period agreement statistic, A, to measure the effect of sample size. $A=0$ if the average within-time period distance is equal to that expected by chance, $\mathrm{A}>0$ if average within-time period distance is less than that expected by chance (McCune and Mefford, 2011).

\section{Results}

Summary pollen data from the shortest record (Uragh Wood) and the NMS ordination of the full Uragh data set are reproduced here to provide an illustration of one of the data sets (Fig. 1). The pollen diagram illustrates how the site was initially dominated by Pinus but this tree declined about 2000 years ago. High charcoal levels in recent centuries are associated with the reduction in tree cover. A successional recovery of the canopy is evident following the reduction in charcoal levels ( Fig. 1a). The NMS ordination recommended a 2-dimensional solution with a final stress of 10.92 and a final instability $<0.00001$. The 
trajectory that the vegetation community takes over the last 3200 years is depicted by vectors joining the pollen samples in ordination space ( Fig. 1b). This ordination illustrates that the current woodland composition was most similar to that of 500 years ago. 

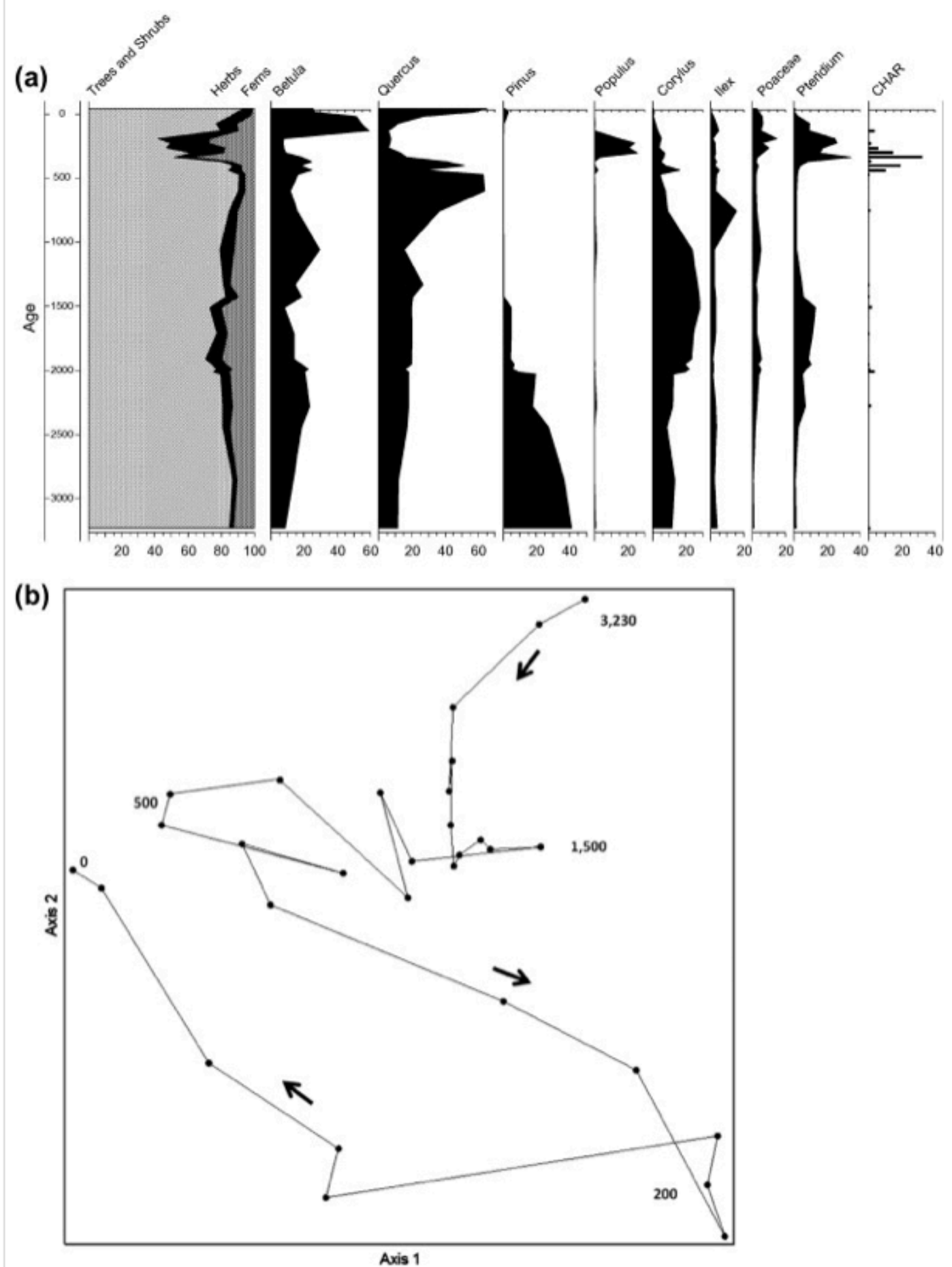

Fig. 1.

Uragh Wood small hollow pollen data (from Little et al. 1996), (a) percentage pollen diagram of a selection of taxa (CHAR is microscopic charcoal accumulation $\left(\mathrm{mm}^{-2} \mathrm{~cm}^{-3} 100\right.$ years ${ }^{-1}$ ). (b) NMS ordination of the full pollen dataset, numbers represent selected time points (years ago) and arrows show chronological direction of the vector.

Figure options $\nabla$

The mean rarefied taxon richness (RareN) across all four sites displays a significant $(p<0.05)$ rise 5000 years ago after which richness remains reasonably constant ( Fig. 2a). The rate of change was highest over the last 1000 
years and relatively low from 6000 to 1000 years ago ( Fig. 2b). Microscopic charcoal was also highest for the last 1000 years with mean CHAR in excess of 25 mm-2 cm-3 100 years-1 (Fig. 2c). Analysis of beta diversity revealed that the oldest samples tended to most different $(>0.5)$ from the present day but that the mean beta diversity for the 2000 to 1000 years ago time period was also greater than 0.5 ( Fig. 2d).

(a)

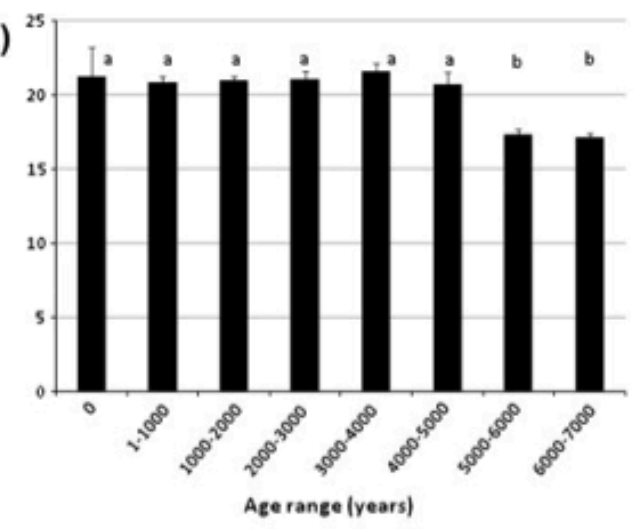

(c)

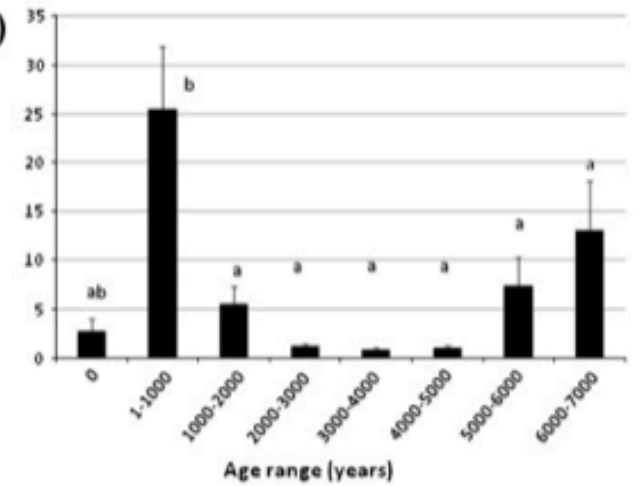

(b)

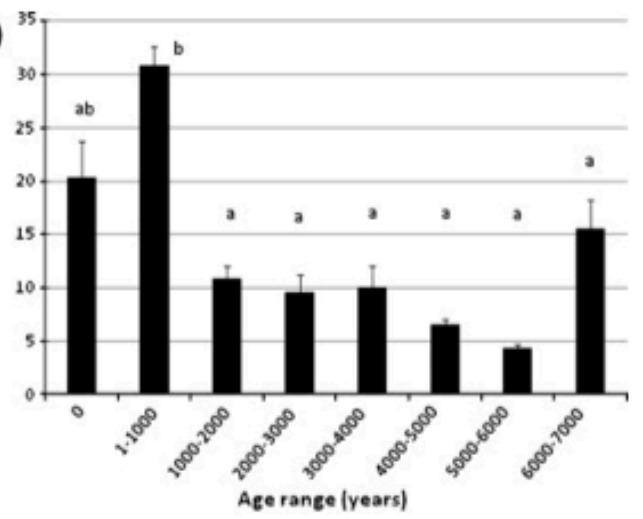

(d)

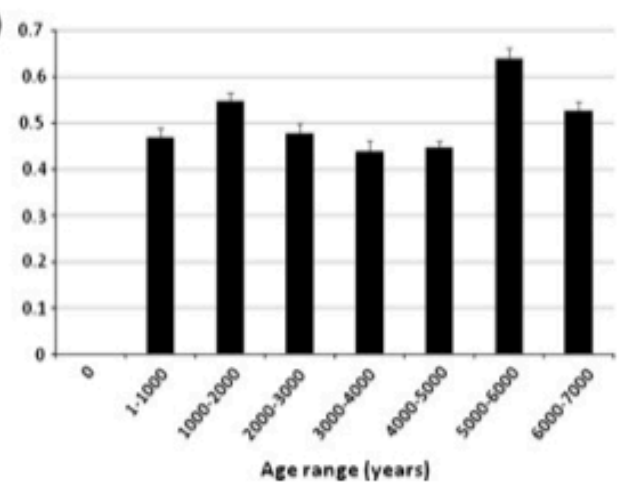

Fig. 2.

Mean ( \pm standard error) values over time periods for the four sites in Table 1, ' 0 ' age range on the $x$-axis represents the surface (present-day) samples. (a) Rarefied taxon richness (RareN); (b) rate of palynological change per 100 years (ROC); (c) microscopic charcoal accumulation rate (CHAR) $\left(\mathrm{mm}^{-2} \mathrm{~cm}^{-3} 100\right.$ years ${ }^{-1}$ ); (d) difference of each time period to the present day (beta). Within each graph, lower-case letters indicate homogenous subsets according to post hoc Mann-Whitney $U$ tests $(p \leqslant 0.05)$.

Figure options $\nabla$

The results of multiple-response permutation procedure (MRPP) revealed a significant difference in the composition between the different time periods $(\mathrm{T}=$ $-13.40, \mathrm{~A}=0.222, \mathrm{p}<0.001$ ). Forest composition during all time periods was significantly different from the present day except for the most recent 1000 years ( Table 2). For the significantly different groups, the values of A are relatively large $(>0.1)$ indicating that the within-time period distances are appreciably smaller than the between-time period distances illustrating distinct differences in forest composition in all of the time periods older than 1000 years ago compared to today. The T-statistics for the 1-1000 years ago time period compared to the older time periods are even more negative, with stronger statistical significance, than comparisons with the present day ( Table 2). 


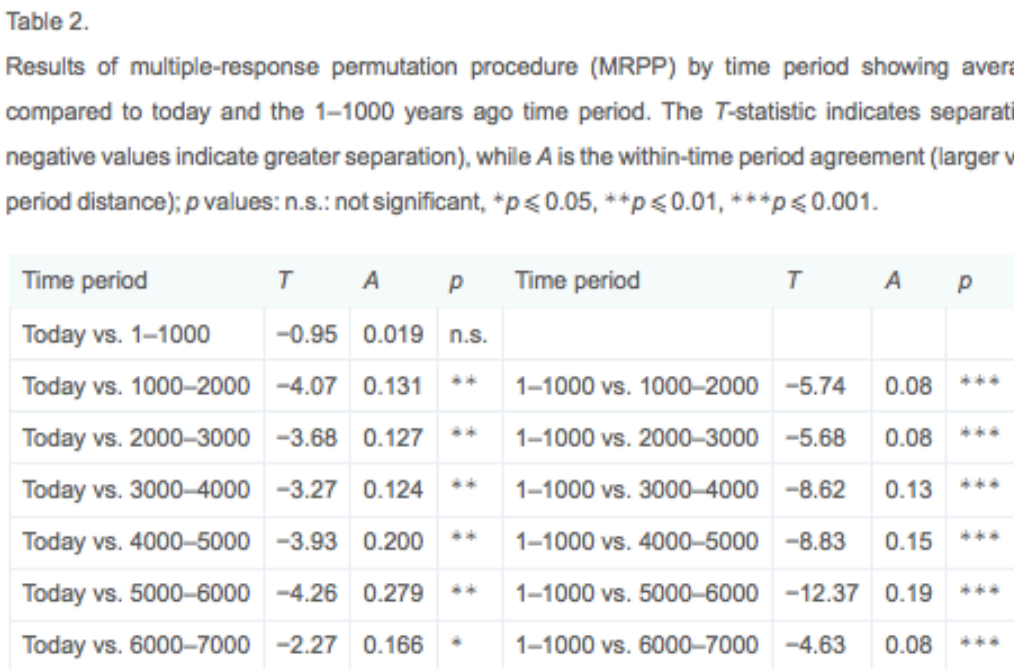

\section{Discussion}

Two factors can be considered as the most significant drivers of compositional change in Irish Atlantic oakwoods. The earliest is the presence of Pinus in these woods before 2000 years ago and the second factor is the intense human exploitation of these woods in recent centuries. Pinus was an early postglacial colonist in Ireland; it spread rapidly up the west coast where it dominated woodland vegetation (Mitchell, 2006). The subsequent expansion of blanket bog severely restricted its distribution and this is associated with the extirpation of Pinus across most of Ireland around 4000 years ago ( Bradshaw and Browne, 1987). Small populations are recorded as surviving in Atlantic woodlands in SW Ireland until at least 2000 years ago ( Mitchell, 1988 and Little et al., 1996) where the presence of the tree appears to have facilitated podzolisation ( Little et al., 1996 and Little et al., 1997). Although Pinus sylvestris stands form viable forest vegetation communities in Ireland today, the tree is no longer considered to be native ( Roche et al., 2009). Consequently the Atlantic oakwoods of highest conservation interest today do not accommodate Pinus sylvestris. These woods now have a canopy dominated by Quercus petraea (Kelly, 2005). This principal difference in forest composition today compared to before 4000 years ago explains the large differences seen in MRPP (both T and A statistics) as well as in alpha and beta diversities. Reduced populations of Pinus survived in the south western Atlantic woods (but not in Brackloon which is further north) until 2000-1500 years ago. This final decline in Pinus contributed to the relatively high beta diversity during the 2000-1000 years ago time period.

Timber extraction, the production of charcoal for iron smelting and the harvesting of oak bark for leather tanning during the 17th, 18th and early 19th centuries resulted in heavy exploitation of Atlantic oakwoods throughout their range. These activities are well documented (McCracken, 1971, Watts, 1984 and 
Smout et al., 2005) and are particularly evident in the Irish, Welsh and Scottish small hollow pollen and charcoal records (Edwards, 1986, Mitchell, 1988, Little et al., 1996, Little et al., 2001 and Sansum, 2004). Mean charcoal accumulation rates in the four Irish sites investigated here are significantly higher over these centuries than any previous time period (Fig. 2c). Such activity would have led to an opening of the canopy and although this did not lead to an increase in taxon richness, it did result in the highest rates of change for any time period.

Pteridium and other herbaceous taxa increase their representation over this time, presumably in response to more light reaching the woodland floor. The Atlantic oakwoods were thus in a dynamic phase of constant flux. The distinctiveness of this exploitation phase (1-1000 years ago) is also evident from the MRPP results when it is compared to earlier time periods. Despite these significant differences in composition, there was no significant change in taxon richness over the last 5000 years. This serves to highlight one of the restrictions of using pollen data where taxonomic resolution is mostly to genus level and small quantities of pollen can be transported to the site from long distances. The application of pollen-vegetation models ( Sugita, 2007b) can account for the latter but not the former. The exploitation phase was not, however, significantly different from the present day woodland which highlights the legacy of the exploitation that is still evident in today's woodlands. The T-statistics for the comparison of the exploitation phase with the pre-exploitation periods indicates that the present day woodland is recovering from exploitation and moving towards earlier compositions.

Many woodlands that were exploited during these recent centuries have not survived. Those that have, were subjected to deliberate management and sylvicultural practices that favoured the most valuable tree, sessile oak (Quercus petraea). These EU Annex 1 habitats thus carry a clear legacy from their previous management because it was implemented to promote the current generation of canopy trees. This has resulted, for example, in an unnaturally high proportion of Quercus in the canopy. Consequently the current structure and composition of Atlantic oakwoods is not sustainable without significant intervention and manipulation.

Travelling back in time to before this exploitation phase we are presented with forest communities that when compared to the present day have a mean beta diversity that is greater than 0.5 so these woodlands were quite different to the present day. The principal difference in the canopy was the presence of Pinus with reduced representation of Betula while the field layer differed through the reduced representation of herbaceous taxa. The rates of change were lower than the last 1000 years suggesting more stability.

So the present day Atlantic woodlands still hold a strong legacy of past exploitation. This raises the question of how we should define these sites and what their conservation management should strive to achieve. Palaeoecological 
data are heralded as providing access to baseline data to facilitate such decisions (Willis et al., 2010) but in this case the data reveal dynamic histories which provide a variety of scenarios, all of which could be classified as baseline. It is however evident that the current structure and composition of these woodlands is unsustainable under their current non-intervention management. Their history suggests that these woodlands are a feature of the cultural, rather than the natural, landscape. Decisions thus need to be made to decide whether they should be managed to maintain their cultural identity or whether this legacy should be lost in favour of a more natural ecosystem.

Acknowledgments

I would like to thank the organisers of the IUFRO Second International Conference on Biodiversity in Forest Ecosystems and Landscapes which was held in Cork in August 2012 where this paper was first presented. I am grateful to Sebastian von Engelbrechten for supplying me with the original pollen data from Brackloon and Uragh woods. I also thank Linda Coote, Anke Dietzsch and Miles Newman for advice on data analysis and referees for helpful comments. 
References

Amar, A., Smith, K.W., Butler, S., Lindsell, J.A., Hewson, C.M., Fuller, R.J., Charman, E.C., 2010. Recent patterns of change in vegetation structure and tree composition of British broadleaved woodland: evidence from large-scale surveys. Forestry $83,345-356$

Baarda, P., 2005. Atlantic oakwoods in Great Britain: factors influencing their definition, distribution and occurrence. Botanical Journal of Scotland 57, 1-19

Birks, H.J.B., 2007. Estimating the amount of compositional change in LateQuaternary pollen-stratigraphical data. Vegetation History and Archaeobotany $16,197-202$

Birks, H.J.B., Line, J.M., 1992. The use of rarefaction analysis for estimating palynological richness from Quaternary pollen-analytical data. The Holocene $2,1-10$

Bradshaw, R., 2007. Pollen methods and studies: stand-scale palynology. In: Elias, S.A. (Ed.), Encyclopedia of Quaternary Science. Elsevier, Oxford, pp. 2535-2543

Bradshaw, R.H.B., Browne, P., 1987. Changing patterns in the post-glacial distribution of Pinus sylvestris in Ireland. Journal of Biogeography 14, 237-248

Brewer, S., Hélyalleaume, C., Cheddadi, R., De Beaulieu, J.-L., Laurent, J.-M., Le Cuziat,

J., 2005. Postglacial history of Atlantic oakwoods: context, dynamics and controlling factors. Botanical Journal of Scotland 57, 41-57 
E.U., 1992. Council Directive 92/43/EEC on the Conservation of natural habitats and

of wild fauna and flora. In: Official Journal L 206, 22/07/1992, pp. 0007-0050. Edwards, M.E., 1986. Disturbance histories of four snowdonian woodlands and their

relation to Atlantic bryophyte distributions. Biological Conservation 37, 301320

Grimm, E.C., Jacobson, G.L., 1992. Fossil-pollen evidence for abrupt climate changes

during the past 18,000 years in eastern North America. Climate Dynamics 6, $179-184$

Hall, J., Stone, D., 2005. Overall biodiversity and the spatial patterns of Atlantic oakwoods. Botanical Journal of Scotland 57, 115-118

Haslett, J., Parnell, A., 2008. A simple monotone process with application to radiocarbon-dated depth chronologies. Journal of the Royal Statistical Society: Series C (Applied Statistics) 57, 399-418

Keith, S.A., Newton, A.C., Morecroft, M.D., Bealey, C.E., Bullock, J.M., 2009. Taxonomic homogenization of woodland plant communities over 70 years. Proceedings of the Royal Society B-Biological Sciences 276, 3539-3544

Kelly, D.L., 2005. Woodland on the western fringe: Irish oak wood diversity and the

challenges of conservation. Botanical Journal of Scotland 57, 21-40

Kirby, K., Smart, S., Black, H., Bunce, R., Corney, P., Smithers, R., 2005. Long term ecological change in British woodland (1971-2001). English Nature Research 
Report No. 653. In: English Nature, Peterborough.

Little, D.J., Boyle, G.M., Ryan, D., Farrell, E.P., 2001. Intensive Monitoring of an Oak Woodland in Western Ireland. COFORD, Dublin

Little, D.J., Farrell, E.P., Collins, J.F., 1997. Land-use legacies and soil development in

semi-natural ecosystems in the marginal uplands of Ireland. Catena 30, 83-98

Little, D.J., Mitchell, F.J.G., von Engelbrechten, S.S., Farrell, E.P., 1996. Assessment of

the impact of past disturbance and prehistoric

Pinus sylvestris

on vegetation

dynamics and soil development in Uragh Wood, S.W. Ireland. The Holocene 6, 90-99

McCracken, E., 1971. The Irish Woods Since Tudor Times. David \& Charles, Newton

Abbot

McCune, B., Mefford, M.J., 2011. PCORD. Multivariate Analysis of Ecological Data Version 6.08. MjM Software, Gleneden Beach, Oregon.

Mihok, B., Kenderes, K., Kirby, K.J., Paviour-Smith, K., Elbourn, C.A., 2009. Fortyyear

changes in the canopy and the understorey in Wytham Woods. Forestry 82, $515-527$

Mitchell, F.J.G., 1988. The vegetational history of the Killarney Oakwoods, S.W. Ireland: evidence from fine spatial resolution pollen analysis. The Journal of Ecology 76, 415-436 
Mitchell, F.J.G., 1990. The impact of grazing and human disturbance on the dynamics of woodland in S.W. Ireland. Journal of Vegetation Science 1, 245254

Mitchell, F.J.G., 2006. Where did Ireland's trees come from? Biology and Environment: Proceedings of the Royal Irish Academy 106B, 251-260

Mitchell, F.J.G., 2011. Exploring vegetation in the fourth dimension. Trends in Ecology \& Evolution 26, 45-52

Nielsen, A.B., Odgaard, B., 2010. Quantitative landscape dynamics in Denmark through the last three 799 millennia based on the Landscape Reconstruction Algorithm approach. Vegetation History and Archaeobotany 19, 375-387

Oksanen, J., Guillaume Blanchet, F., Kindt, R., Legendre, P., Minchin, P.R., O’Hara, R.B.,

Simpson, G.L., Solymos, P., Henry, M., Stevens, H., Wagner, H., 2012. Vegan:

Community Ecology Package, version 2.0-5. In.

Onaindia, M., Dominguez, I., Albizu, I., Garbisu, C., Amezaga, I., 2004. Vegetation diversity and vertical structure as indicators of forest disturbance. Forest Ecology and Management 195, 341-354

Overballe-Petersen, M.V., Bradshaw, R.H.W., 2011. The selection of small forest hollows for pollen analysis in boreal and temperate forest regions. Palynology $35,146-153$

Overballe-Petersen, M.V., Nielsen, A.B., Bradshaw, R.H.W., 2013. Quantitative vegetation reconstruction from pollen analysis and historical inventory data around a Danish small forest hollow. Journal of Vegetation Science. 
http://

dx.doi.org/10.1111/jvs.12007

Peterken, G.F., Jones, E.W., 1987. Forty years of change in Lady Park Wood: the old-

growth stands. The Journal of Ecology 75, 477-512

Peterken, G.F., Jones, E.W., 1989. Forty years of change in Lady Park Wood: the young-growth stands. The Journal of Ecology 77, 401-429

R Core Team, 2012. R: a language and environment for statistical computing. In: $\mathrm{R}$

Foundation for Statistical Computing, Vienna, Austria.

Roche, J.R., Mitchell, F.J.G., Waldren, S., 2009. Plant community ecology of Pinus sylvestris, an extirpated species reintroduced to Ireland. Biodiversity and Conservation 18, 2185-2203

Sansum, P.A., 2004. Historical resource use and ecological change in semi-natural woodland: Western oakwoods in Argyll, Scotland. In: University of Stirling, PhD Thesis.

Seppä, H., 2007. Pollen analysis, principles. In: Elias, S.A. (Ed.), Encyclopedia of Quaternary Science. Elsevier, Oxford, pp. 2486-2497

Silvertown, J., Tallowin, J., Stevens, C., Power, S.A., Morgan, V., Emmett, B., Hester, A.,

Grime, P.J., Morecroft, M., Buxton, R., Poulton, P., Jinks, R., Bardgett, R., 2010.

Environmental myopia: a diagnosis and a remedy. Trends in Ecology \&

Evolution 25, 556-561

Smout, T.C., MacDonald, A.R., Watson, F., 2005. A History of the Native Woodlands 
of Scotland, 1500-1920. Edinburgh University Press Edinburgh

Sugita, S., 1994. Pollen representation of vegetation in Quaternary sediments: theory and method in patchy vegetation. The Journal of Ecology 82, 881-897

Sugita, S., 2007a. Theory of quantitative reconstruction of vegetation I: pollen from

large sites REVEALS regional vegetation composition. Holocene 17, 229-241

Sugita, S., 2007b. Theory of quantitative reconstruction of vegetation II: all you need

is LOVE. Holocene 17, 243-257

Sugita, S., Parshall, T., Calcote, R., Walker, K., 2010. Testing the Landscape

Reconstruction Algorithm for spatially explicit reconstruction of vegetation in northern Michigan and Wisconsin. Quaternary Research 74, 289-300

Watts, W.A., 1984. Contemporary accounts of the Killarney woods 1580-1870. Irish

Geography 17, 1-13

Willis, K.J., Bailey, R.M., Bhagwat, S.A., Birks, H.J.B., 2010. Biodiversity baselines, thresholds and resilience: testing predictions and assumptions using palaeoecological data. Trends in Ecology \& Evolution 25, 583-591 